TAHAP PERKEMBANGAN KOGNITIF PESERTA PROGRAM PENDIDIKAN MORAL DAN ETIKA TENTARA DALAM ANGKATAN TENTARA MALAYSIA

\title{
Azri Mokhtar
}

Fakulti Pendidikan Universiti Malaya (UM) Malaysia

\section{Wan Hasmah Wan Mamat}

Fakulti Pendidikan Universiti Malaya (UM) Malaysia

$$
\text { Ghazali Darussalam }
$$

Fakulti Pendidikan Universiti Malaya (UM) Malaysia

\section{Triyo Supriyatno}

Fakultas Ilmu Tarbiyah dan Keguruan UIN Maulana Malik Ibrahim

\author{
Malang
}

\begin{abstract}
This article discusses about cognitive development among military personnel in the Moral and Military Ethical Education programs (MMEE) in the Malaysian Armed Forces (MAF). This study was conducted to evaluate the influence of the elements used in the MMEE's program to cognitive performance among the participants. A total of 469 participants took a moral and military ethical (MME) achievement test and the data were analyzed using multiple regression analysis. The findings show that, out of the five key elements of MMEE's program, elements of the table shows that there is a significant contribution to cognitive achievement by the contribution of $=1.4 \%$. The remaining elements of the syllabus, facilities, location and teaching and learning process of each show there is no significant contribution to cognitive achievement among the participants.
\end{abstract}

Keywords: Cognitive development , MMEE's program, elements, MME's achievement, contributions. 
Abstrak: Artikel ini membahas tentang perkembangan kognitif antara personil militer di program Moral dan Pendidikan Etika Militer (MME) di Angkatan Bersenjata Malaysia (MAF). Penelitian ini dilakukan untuk mengevaluasi pengaruh unsur-unsur yang digunakan dalam program MMEE untuk melatih kinerja kognitif para peserta. Sebanyak 469 peserta mengambil tes Moral dan Pendidikan Etika Militer (MME) dan data dianalisis dengan menggunakan analisis regresi berganda. Temuan menunjukkan bahwa, dari lima elemen kunci dari program MMEE ini, unsur-unsur yan terdapat pada tabel menunjukkan bahwa ada kontribusi signifikan terhadap prestasi kognitif dengan kontribusi $=1,4 \%$. Unsur-unsur yang tersisa dari proses silabus, fasilitas, lokasi, pengajaran dan pembelajaran masing-masing menunjukkan tidak ada kontribusi yang signifikan terhadap prestasi kognitif di antara para peserta.

Kata-Kata Kunci: perkembangan kognitif, program MME, elemen, prestasi MME, kontribusi.

\section{Pendahuluan}

Di dalam menjalankan amanah dan menjaga kasuselamatan negara, anggota tentara yang mempunyai autoriti dan pertimbangan tertentu seharusnya dipandu oleh nilai-nilai diri yang unggul agar setiap kuasa yang diperuntukkan oleh undang-undang itu dapat dijalankan dengan profesional dan sempurna. Selain itu, jiwa yang disemai dengan nilai moral dan etika akan dapat menghindari setiap tindakan di luar batasan yang diperuntukkan. Hasrat ini bersesuaian dengan Mattox (2005) yang menekankan bahwa nilai akhlak yang tinggi bagi anggota tentara sangat perlu karena ianya menghasilkan satu imperatif moral yaitu memiliki sifat belas kasihan yang mendalam, mementingkan keadilan dan memiliki kewibawaan serta berupaya membedakan antara perlakuan yang mewajarkan keganasan atau sebaliknya sewaktu peperangan. 
Menyadari hakikat bahwa sistem latihan melalui pemberian ganjaran dan mengenakan hukuman tidak memadai untuk memastikan tingkah laku moral diamalkan (Martinelli-Fernandez, 2006), maka dengan itu ATM telah memperkenalkan program Pendidikan Moral dan Etika Tentara (PMET) di bawah Pemerintahan Medan Tentara Darat mulai tahun 2006. Langkah ini seiring dengan Konsep Pendidikan ATM yaitu sebagai satu usaha berterusan untuk melahirkan warga ATM yang berilmu pengetahuan dan seimbang dari segi emosi, rohani, intelek dan jasmani (Arahan Pentadbiran Pendidikan ATM, 2008). Usaha ini akan menjamin satu proses pendidikan yang berterusan dalam membekalkan pengetahuan dan pengalaman baru ke arah melahirkan anggota tentara yang berpribadi unggul. Tindakan ini seiring dengan pendapat Davidson (2005: 227) yaitu, "pendidikan karakter adalah satu proses di mana individu dibina watak melalui interaksi domain kognitif yang sudah ada, pengalaman baru dan pengaruh orang di sekeliling mereka."

Dalam meningkatkan kemampuan modal insan ATM agar memenuhi keperluan visinya yaitu Menjadi Sebuah Angkatan Tentara Yang Versatil Pada Abad Ke-21, struktur pendidikan ATM telah menggariskan sebanyak lima kategori pendidikan dalam ATM yaitu Pendidikan Individu, Pendidikan Profesional Tentara, Pendidikan Dalam Latihan, Pengajian Tinggi dan Pendidikan Akhlak (Arahan Pentadbiran Pendidikan ATM, 2008). Menyentuh mengenai pendidikan akhlak, tinjauan kajian mendapati pelaksanaannya perlu diberi penekanan dan diperkemaskan agar kelima-lima struktur pendidikan ATM dapat didukung secara bersepadu.

Seiring dengan dasar ATM menetapkan lulus ujian penguasaan Moral dan Etika Tentara (MET) sebagai salah satu daripada syarat kenaikan pangkat bagi anggota yang bukan beragama Islam berkuatkuasa tahun 2013, maka pelaksanaan program PMET tersebut telah diperluaskan ke seluruh perkhidmatan dalam ATM yaitu Tentara Darat Malaysia (TDM), Tentara Laut DiRaja Malaysia (TLDM) dan Tentara Laut DiRaja Malaysia (TUDM). Bagi memenuhi aspirasi ini, pelakasaan program Pendidikan Moral dan Etika Tentara (PMET) harus di nilai semula agar pelaksanaannya mampu memberi impak 
dalam meningkatkan penguasaan Moral dan Etika Tentara (MET) dalam kalangan anggota tentara.

Menurut Mohd Radzi (2006), ATM kini sedang menghadapi permasalahan terhadap tahap kualiti keanggotaannya ekoran daripada beberapa kejadian yang menjurus kepada penurunan aspek pengamalan etika dan nilai, yaitu ciri-ciri yang merupakan di antara tunggak utama kepada ATM. Peningkatan atau penglibatan statistik kasus-kasus kejahatan dan salah laku dalam kalangan anggota tentara harus dilihat dan ditangani secara serius (Laporan Sel Provos Markas Medan Tentara Darat, 2012). Laporan Sel Provos Markas Medan Tentara Darat (2012) menunjukkan unjuran kasus-kasus yang melibatkan anggota-anggota di bawah pemerintahan seperti berikut:

Jadwal 1 : Statistik Kasus Penyimpangan Perilaku Anggota di Bawah Pemerintahan Medan Tentara Darat Tahun 2008 hingga 2011

\begin{tabular}{lrrrr}
\hline Jenis Kasus & $\mathbf{2 0 0 8}$ & $\mathbf{2 0 0 9}$ & $\mathbf{2 0 1 0}$ & $\mathbf{2 0 1 1}$ \\
NARKOBA & 206 & 376 & 307 & 235 \\
Kejahatan & 224 & 281 & 394 & 219 \\
Tata Tertib Umum & 154 & 174 & 340 & 403 \\
Tidak Hadir Tanpa Libur & 554 & 381 & 423 & 369 \\
\hline
\end{tabular}

\section{Tujuan Kajian}

Kajian ini bertujuan untuk menilai pengaruh program PMET dalam ATM. Objektif kajian pula adalah untuk melihat kontribusi program PMET terhadap penguasaan kognitif, dalam kalangan anggota peserta.

\section{Manfaat Kajian}

Di dalam membariskan anggota ATM dengan ciri-ciri pribadi unggul, maka pendidikan pembinaan akhlak seperti program PMET ini harus dijalankan dengan pengaruh. Untuk menjadikan program PMET sebagai suatu program yang mampu meningkatkan perkembangan kognitif MET dalam kalagan anggota peserta, maka penilaian masalah 
program haruslah dijalankan. Hasil kajian ini kelak dapat dijadikan panduan kepada usaha penambahbaikan terhadap program ini serta menjadi asas kepada kajian lanjut.

\section{Batasan Kajian}

Bagi kajian ini, sampel yang digunakan hanya terbatas kepada anggota peserta yaitu anggota tentara yang mengikuti program PMET saja . Dengan itu, hasil kajian yang diperolehi tidak dapat digeneralisasikan kepada anggota-anggota yang tidak mengikuti program PMET. Selain daripada itu, hasil kajian ini juga tidak boleh digeneralisasikan kepada kursus atau program lain dalam ATM. Justru, dapat kajian ini hanya boleh digunakan untuk merumuskan keadaan dan situasi pelaksanaan program PMET dalam ATM (TDM, TLDM dan TUDM) saja .

\section{Kajian Literatur}

Sebagai sebagian komuniti masyarakat, anggota ATM juga turut terdedah kepada gejala ini dan secara tidak langsung turut menyumbang kepada peningkatan statistik gejala sosial negara (Laporan Sel Provos, Markas medan Tentara Darat 2012). Proses penularan budaya hedonisme dari Barat sedikit sebanyak telah mencemarkan budaya tempatan dan melonggarkan sistem kawalan sosial serta menghakis budaya ketimuran yang menjadi amalan masyarakat Malaysia selama ini. Menurut Moha Asri (1997), keruntuhan nilai sosial di kalangan masyarakat di Malaysia bukanlah sesuatu yang baru. Ia dikatakan mula menular dalam kehidupan masyarakat Malaysia pada awal tahun 1960-an. Malah peningkatan gejala keruntuhan nilai sosial ini semakin berleluasa pada akhir tahun 1980-an sampai saat ini.

Sebagai salah satu langkah bagi memperkasakan keunggulan diri anggota ATM, maka program PMET harus dipersiapkan supaya pelaksanaannya tidak bermasalah dan mencapai tujuan program. Justru, kajian ini telah memfokuskan kepada masalah program PMET dalam meningkatkan penguasaan MET dalam kalangan anggota 
peserta program. Di dalam menilai sesuatu program pendidikan atau latihan, terdapat pelbagai pendekatan penilaian yang dikemukan oleh pakar-pakar penilaian program untuk melihat tahap problem suatu program. Stufflebeam dan Shinkfield (1990) berpendapat bahwa pendekatan penilaian dapat dibagi menjadi pendekatan penilaian pseudo, penilaian semu dan penilaian realistis. Trochim (1999) berpendapat bahwa terdapat empat pendekatan dalam melaksanakan penilaian program yaitu berdasarkan orientasi model penelitian saintifik, sistem manajemen, antropologi atau model kualitatif dan peserta program. Kajian ini telah mengadaptasi Model Logik Universiti Winconsin (2002) dan Model Hammond (1973).

Model logik adalah cara visual yang menggambarkan teori perubahan (Frechtling, 2007). Menurutnya, teori perubahan menerangkan bagaimana sekumpulan pencapaian awal dan pertengahan menetapkan peringkat untuk menghasilkan keputusan jangka panjang. Model ini diadaptasi untuk melihat sejauhmanakah kemampuan elemen-elemen program PMET dalam memberi impak. Memandangkan kajian ini bertujuan untuk melihat problematika program terhadap objektif yaitu tahap penguasaan MET anggota peserta dalam ketiga domain yaitu kognitif, afektif dan psikomotor, maka kajian ini juga turut mengadaptasi Model Hammond (1973).

Dalam konteks ketentaraan tidak banyak penelitian empirikal dijalankan mengenai keberkasusanan pendidikan karakter dan pendidikan moral dalam tentara (Williams, 2010). Beliau menyatakan hanya sedikit penelitian dijalankan bagi menangani kemerosotan aspek karakter, problematika proses melahirkan anggota tentara bermoral dan persediaan untuk melakukan yang sepatutnya dalam suasana peperangan dan kehidupan sipil. Untuk melahirkan seorang perwira, angkatan tentara itu tidak boleh sekedar memberi tumpuan kepada latihan ketentaraan semata-mata, namun sebagai bagian daripada rakyat sebuah negara, anggota tentara sepatutnya menjadi warganegara teladan (Snider, 2008). Anggota tentara mesti menjadi contoh moral di dalam suasana peperangan maupun dalam keadaan aman. Mereka mesti berpegang teguh kepada nilai-nilai tentara dan nilai-nilai nasional semasa menjalankan tugas. 
Nilai akhlak yang tinggi sangat perlu karena ianya menuntut satu imperatif moral yaitu memiliki sifat belas kasihan yang mendalam, mementingkan keadilan dan memiliki kewibawaan serta berupaya membedakan antara perlakuan yang mewajarkan keganasan atau sebaliknya semasa peperangan (Mattox, 2005). Lapsley \& Narvaez (2006) menyatakan satu model pendidikan etika boleh dimasukkan ke dalam program-program profesional seperti Pendidikan Etika Bersepadu (PEB). Menurut mereka, PEB adalah memusatkan kepada tiga komponen utama yaitu pemupukan karakter bagi membangunkan kepakaran etika, kepentingan kendiri dalam membangun etika dan mengekalkan sifat mulia. Pada masa yang sama perlu memupuk kepakaran dua aspek yaitu pemahaman tersurat dan tersirat (Lapsley \& Narvaez, 2006). Laporan Institut Kajian Tentara Amerika mensyorkan aplikasi pendidikan karakter dalam pelbagai latihan ketentaraan. Kaedah ini secara tidak langsung menganggap bahwa tentara akan membangunkan karakter menerusi aktiviti atau latihan yang dijalankan. Keadaan ini dirujuk sebagai kurikulum tersembunyi dengan tanggapan bahwa karakter boleh dibangunkan melalui aktivitas-aktivitas selain daripada secara kognitif (Power, Higgins \& Kohlberg, 1989).

Dari segi penguasaan moral dan etika pula, Messick (1976) berpendapat bahwa terdapat hubungan dan kaitan antara domain afektif dan kognitif. Dalam domain afektif terkandung objektif-objektif yang menerangkan perubahan-perubahan daripada segi minat, sikap, nilai, perkembangan apresiasi dan penyesuaian yang mencukupi. Tujuan afektif ini berubah-ubah daripada perhatian biasa terhadap fenomena yang tertentu sampai kepada ciri-ciri dalaman bagi perwatakan dan suara hati yang konsisten tetapi kompleks (Abdul Razak, 2007). Seterusnya domain psikomotor ialah bidang yang mementingkan manipulasi dan kemahiran serta pengendalian bahan dan objek yang dimanipulasi atau beberapa tindakan yang memerlukan koordinasi otot saraf.

Bagi ATM, penilaian program PMET juga turut memfokuskan kepada ketiga-tiga domain yaitu pengetahuan, afektif serta amalan nilai moral dan etika tentara (Sukatan Pelajaran Program PMET, 2006). Sukatan Pelajaran Program PMET (2006) menguraikan bahwa 
pengetahuan moral dan etika terdiri daripada maklumat dan idea asas yang mana anggota tentara perlu tahu serta menggunakannya untuk menjadi individu tentara yang bertanggungjawab dan unggul nilai akhlaknya. Informasi asas ini merangkumi nilai dari sifat-sifat individu yang berakhlak mulia dan nilai etika tentara. Perasaan moral dan etika tentara pula adalah untuk melahirkan insan yang berakhlak mulia dan individu tentara yang bertanggungjawab terhadap organisasi, raja dan negara. Manakala perlakuan moral dan etika tentara terdiri daripada tindakan dan penglibatan diri anggota tentara dalam aktiviti-aktiviti di dalam dan luar organisasi yang membolehkan mereka membuat keputusan serta menyelesaikan masalah. Amalan ini juga dapat meningkatkan kasusedaran moral dan membolehkan mereka memberi kontribusi terhadap pembangunan ATM, masyarakat dan negara.

Teori Perkembangan Moral Kognitif menyatakan bahwa perubahan dalam pertimbangan moral adalah berdasarkan tahap yaitu seseorang ditantang dengan pertimbangan moralnya dan tidak memadai jika hanya mengambil satu metode pendidikan moral untuk membangunkan pertimbangan moral. Teori ini juga menyatakan bahwa pembangunan moral memerlukan pelajar mengambil peranan dengan menjiwai dan bersimpati dengan orang lain. Instrumen ini telah disahkan secara empirik menerusi perbincangan dilema kumpulan kecil (Bebeau, 2002; Berkowitz \& Gibbs, 1983; King \& Mayhew, 2002).

Dalam hal ini, Messick (1976) menyatakan terdapat hubungan dan saling berkaitan antara domain afektif dan kognitif. Pendapat ini seiring dengan Wan Hasmah (2000) yang menegaskan di dalam membangunkan para pelajar pendidikan moral, penekanan bukan saja diberikan kepada aspek kognitif semata-mata tetapi juga aspek afektif. Menurut Vishalache (2011, 2009 a), kemoralan seharusnya melibatkan perkembangan emosi yang ditransformasikan melalui perilaku selaras dengan kemampuan perkembangan moral individu. Pembangunan pelajar secara seimbang dalam ketiga-tiga domain kognitif, afektif dan perlakuan adalah amat penting terutamanya dalam menghadapi tantangan isu akhlak dan moral masa kini. Pembangunan pelajar secara seimbang juga telah dipaparkan oleh Lickona (1993) yang menggariskan tiga konsep yang diperlukan dalam melaksanakan 
pendidikan karakter yang dinamakan pemikiran moral, perasaan moral dan tingkahlaku moral.

Kajian Azri (2009) menunjukkan pencapaian kognitif bagi anggota tentara program PMET adalah pada tahap sederhana yaitu nilai min 2.417 dan sisihan piawai 0.969 , pencapaian afektif adalah pada tahap memuaskan dengan nilai min 4.137 dengan sisihan piawai 0.777 dan bagi pencapaian psikomotor pula adalah pada tahap baik dengan nilai rata-rata min 2.24 dan sisihan piawai 0.860. Dari segi perbedaan pencapaian dan latar belakang individu pula, pencapaian kognitif menunjukkan wanita hampir sama dengan anggota laki-laki, bagi pencapaian afektif tentara wanita menunjukkan pencapaian afektif lebih tampak berbanding laki-laki manakala pencapaian tingkah laku pula menunjukkan tentara laki-laki lebih tinggi mengatasi wanita. Seterusnya kajian tersebut menunjukkan bahwa, persepsi anggota tentara terhadap dimensi pengajaran yaitu kaedah pengajaran dan kemudahan program pada tahap amat memuaskan dengan masing-masing nilai min 4.208 dan 4.226 serta nilai sisihan piawai 0.704 dan 0.721. Bagi pengurusan organisasi adalah pada tahap memuaskan dengan nilai min 4.042 dan sisihan piawai 0.818 .

Kajian yang dilakukan oleh Abdul Rani Mohd Yusuf (1991), mendapati permasalahan tingkah laku rugi diri anggota tentara seperti berjudi, minum arak, berhubung dan tidak bertanggungjawab adalah berkait rapat dengan pengetahuan agama Islam. Beliau juga mendapati, kurangnya penghayatan agama menpengaruhi tingkah laku rugi diri yang menjurus kepada aspek negatif tersebut dan seterusnya melibatkan tingkah laku yang membawa kepada pelanggaran disiplin di dalam ATM. Williams (2010) juga berpandangan bahwa isi dan metode Latihan Awal Kemasukan Polis Tentara seolah-olah tidak mempunyai masalah dalam pertimbangan moral tentara, sebaliknya cenderung untuk mengukuhkan norma skema pertimbangan moral yaitu pendekatan yang berasaskan peraturan untuk membuat keputusan moral. Menurutnya, hubungan pemimpin dan anggota bawahan muncul sebagai pengaruh yang paling utama terhadap masalah pendidikan moral dan pendidikan karakter. Budaya tentara didapati cenderung menjadi penghalang dalam membangun 
pertimbangan moral yang diperlukan untuk masa depan operasi ketentaraan yang lebih fleksibal.

Oleh karena itu, terdapat keperluan dalam menilai kriteria bagi menjalankan analisis terhadap keberkasusanan program etika ketentaraan. Menurut Webster (2003), masalah bermakna menghasilkan kasus yang dikehendaki dan menilai masalah dalam membuat keputusan dalam program etika ketentaraan memerlukan garis panduan. Di samping keputusan yang dihasilkan, terdapat kriteria-kriteria lain yang berkaitan apabila menilai masalah panduan membuat keputusan. Josephson (2002) menggariskan dua langkah yang perlu apabila berhujah mengenai prinsip yang melibatkan etika yaitu penjelasan dan penilaian persoalan etika.

\section{Metodologi Penelitian}

1. Disain Kajian dan Instrumen Kajian

Disain kajian ini adalah kajian tinjauan yaitu menggunakan instrumen kuesioner dan ujian penguasaan MET untuk melihat masalah program PMET yang dilaksanakan dalam ATM. Fokus kajian ini adalah untuk mendapat jawaban daripada responden terhadap masalah program PMET yang dijalankan dalam ATM. Sampel kajian ini merupakan populasi sebenar anggota peserta, fasilitator dan pemerintah yang terlibat dengan program PMET pada bulan September hingga Disember 2013. Sampel kajian ini merangkumi keempat-empat divisyen penempatan anggota ATM. 1 Divisyen adalah penempatan di Sabah dan Sarawak, 2 Divisyen merupakan penempatan di Utara Semenanjung Malaysia, 3 Divisyen di Selatan Semenanjung Malaysia dan 4 Divisyen di Bahagian Tengah Semenanjung Malaysia. Pecahan populasi sampel kajian mengikut penempatan anggota dalam ATM seperti jadwal berikut:

Jadwal 2 : Bilangan Sampel Anggota Peserta, Fasilitator dan Pemerintah Mengikut Divisyen

\begin{tabular}{cccc}
\hline Divisyen & $\begin{array}{c}\text { Anggota } \\
\text { Peserta }\end{array}$ & Fasilitator & $\begin{array}{c}\text { Pemerintah } \\
\text { Pasukan }\end{array}$ \\
\hline 1 Divisyen & 220 & 6 & 5 \\
2 Divisyen & 138 & 8 & 7 \\
\hline
\end{tabular}




\begin{tabular}{cccc}
\hline 3 Divisyen & 59 & 8 & 8 \\
3 Divisyen & 52 & 11 & 11 \\
\hline JUMLAH & 469 & 33 & 32 \\
\hline
\end{tabular}

\section{Teknik Analisis Data}

Dalam kajian ini, proses menganalisis data melibatkan dua jenis statistik yaitu deskriptif dan inferensi. Untuk menjalankan analisis, proses pengkodan akan dijalankan untuk memudahkan aktivitas memasukkan data. Data statistik deskriptif digunakan untuk melihat dan menghuraikan secara menyeluruh tentang latar belakang responden seperti bangsa, jantina, umur, taraf perkahwinan, pangkat yang disandang, lama perkhidmatan dalam ATM, lama mengajar PMET, lama menjawat jawatan sekarang dan kelulusan akademik. Skor, kekerapan, prosentase, min dan sisihan lazim akan dilihat dalam analisis statistik deskriptif ini. Statistik inferensi pula untuk membuat anggaran tentang satu indeks populasi dengan menggunakan satu indeks statistik dari satu sampel yang representatif (Alias Baba,1992). Berdasarkan masalah kajian, analisis yang akan dijalankan dalam statistik inferensi kategori ANOVA Sehala dan Regresi Berganda.

\section{Hasil Kajian}

Masalah Program PMET adalah adalah merujuk kepada kontribusi elemen-elemen utama program PMET yaitu kurikulum pelajaran, jadwal, kemudahan, tempat dan PdP. Jadwal 3 hingga 6 adalah data analisis regresi berganda yang dijalankan pada aras signifikan 0.05 yang menunjukkan perkaitan atau kontribusi program PMET terhadap penguasaan MET anggota peserta (kognitif, afektif dan psikomotor). Hipotesis mengenai kontribusi elemen-elemen utama terhadap penguasaan kognitif adalah seperti berikut: 
Ho.1 Tidak terdapat kontribusi yang signifikan oleh sukatan pelajaran program PMET terhadap penguasaan kognitif.

Ho.2 Tidak terdapat kontribusi yang signifikan oleh jadwal program PMET terhadap penguasaan kognitif.

Ho.3 Tidak terdapat kontribusi yang signifikan oleh kemudahan program PMET terhadap penguasaan kognitif.

Ho.4 Tidak terdapat kontribusi yang signifikan oleh tempat pelaksanaan program PMET terhadap penguasaan kognitif.

Ho.5 Tidak terdapat kontribusi yang signifikan PdP program PMET terhadap penguasaan kognitif.

Bagi penguasaan aspek kognitif, Jadwal 3 menjelaskan kasus semua elemen program PMET menunjukkan hubungan yang tidak signifikan yaitu nilai $\mathrm{P}>0.05$ kecuali elemen jadwal. Data menunjukkan elemen jadwal menghasilkan nilai Beta $=0.202$, nilai $\mathrm{t}=$ 2.641 dan nilai $\mathrm{P}=0.009$. Analisis regresi berganda seterusnya menunjukkan nilai $\mathrm{R}$ bagi jadwal $=0.194$, $\mathrm{R}$ ganda $2=0.037$ dan nilai ralat piawai $=2.075$. Nilai korelasi $(\mathrm{R})$ yang ditunjukkan adalah kuat, yaitu terdapat hubungan di antara kedua variabel yang dikaji yaitu jadwal dan penguasaan kognitif. Kecerunan yang positif ini menunjukkan korelasi kedua-dua variabel adalah berkadar terus. Seterusnya apabila nilai pekali korelasi dikuasaduakan, maka $\mathrm{R}$ ganda $2=0.037$. Data ini menunjukkan jumlah varians yang dikongsi bersama oleh variabel tersebut ialah $3.7 \%$. Selanjutnya nilai $\mathrm{R}$ diubah suai $=0.014$. Dengan ini hasil analisis regresi berganda menunjukkan problem program PMET yang disumbang oleh elemen jadwal program terhadap penguasaan kognitif anggota peserta $=1.4 \%$.

Hasil kajian ini telah membukti bahwa andaian tidak terdapat kontribusi yang signifikan oleh kurikulum pelajaran, kemudahan, tempat dan PdP program PMET terhadap penguasaan kognitif (Ho.1, Ho.3, Ho4 dan Ho.5) adalah tidak berjaya ditolak. Sebaliknya andaian tidak terdapat kontribusi yang signifikan oleh jadwal program PMET terhadap penguasaan kognitif (Ho.2) berjaya ditolak. Justru, Ho.1, Ho.3 Ho.4 dan Ho.5 adalah diterima (tidak berjaya ditolak) dan Ho.2 adalah tidak diterima (berjaya ditolak). 
Jadwal 3 : Analisis Regresi Berganda Kontribusi Elemen Program PMET Terhadap

\section{Penguasaan Kognitif}

\begin{tabular}{llclccc}
\hline Penguasaan & Elemen & B & Ralat & Beta & t & Sig \\
& & & Piawaii & & & \\
Kognitif & kurikulum & -.333 & .336 & -.085 & -.993 & .321 \\
& Jadwal & .668 & .253 & .202 & 2.641 & .009 \\
& Kemudahan & .051 & .237 & .017 & .216 & .829 \\
& Tempat & -.162 & .294 & -.046 & -.550 & .583 \\
& PdP & -.521 & .499 & -.133 & -1.045 & .297 \\
& & & & & & \\
& Analisis & $\mathrm{R}$ & $\mathrm{R}$ & Ubahsua & Ralat & Kontribusi \\
& Regresi & 0.194 & Ganda & i R & Piawai & $1.4 \%$ \\
& & & 2 & 0.014 & 2.075 & \\
& & & 0.037 & & & \\
\hline
\end{tabular}

\section{Pembahasan}

Regresi berganda digunakan sebagai metod analisis untuk melihat keberkasusanan adaptasi teori Model Hammond (1973) dan Model Logik Universiti Winconsin (2002) yang dijadikan sandaran dalam kajian ini. Enam elemen pelaksanaan program PMET di analisis menggunakan ujian regresi berganda yaitu sukatan pelajaran, jadwal, kemudahan, tempat, kewangan, sokongan pemerintah dan PdP. Analisis regresi berganda ini digunakan bagi memenuhi objektif kajian dan menjawab persoalan tentang sejauhmanakah kontribusi elemenelemen program PMET terhadap penguasaan kognitif anggota peserta. Jadwal 3 menjelaskan bahwa kasus semua elemen yang terdapat dalam program PMET menunjukkan tidak terdapat kontribusi yang signifikan terhadap penguasaan kognitif kecuali elemen jadwal. Dapatan ini menunjukkan jadwal program PMET yang disediakan telah disusun dengan rapi dan mampu menguraikan kurikulum pelajaran yang berunsur kognitif seperti ceramah-ceramah yang disusun dalam program ini. Dapatan ini juga menunjukkan jadwal telah memperuntukkan masa yang sesuai dengan keperluan kurikulum 
pelajaran yang mengandungi 24 nilai dan etika tentara. Kesesuaian ini telah menjadikan elemen jadwal mampu memberikan kontribusi yang signifikan terhadap penguasaan kognitif anggota peserta dalam konteks kurikulum pelajaran semasa yang disediakan. Dapatan ini seiring dengan kajian-kajian terdahulu seperti Fowziah (1991) dan Sharifah (1990) yang mendapati jadwal yang disusun dengan teratur akan melancarkan proses pengajaran dan pembelajaran serta akan meningkatkan problem pengajaran. Walaupun demikian, kajian mendapati elemen kurikulum pelajaran, kemudahan dan PdP tidak memberi kontribusi yang signifikan terhadap penguasaan kognitif.

\section{Kesimpulan}

Secara kasuseluruhannya, kajian ini menunjukkan hanya elemen jadwal yang memberikan kontribusi yang signifikan terhadap penguasaan kognitif anggota peserta dengan nilai kontribusi sebanyak 1.4\% (Jadwal 2).Sungguhpun prosentase kontribusi elemen jadwal terhadap penguasaan kognitif kecil, namun kontribusinya adalah signifikan dan membantu untuk meningkatkan program PMET. Dengan itu, data mendapati umumnya elemen-elemen program PMET tidak memberi kontribusi yang signifikan kepada pencapaian kognitif dan diklasifikasikan sebagai elemen-elemen tersebut interaksi tidak berlaku pada tahap yang tinggi. Hasil kajian ini memberi petunjuk bahwa program PMET yang dilaksanakan dalam ATM memerlukan kajian penilaian selanjutnya untuk memperbaiki masalah pada program PMET yang dijalankan.

Saran ini sesuai dan melihat bahwa program PMET ini masih di peringkat percobaan yang memungkinkan terdapat jurang yang besar dalam segenap aspek dan memerlukan input-input usulan dari penelitian yang dijalankan untuk dibuat penambahbaikan. Program PMET yang bermasalah sewajarnya mempunyai sumbersumber dan elemen-elemen utama program yang berupaya memberikan kontribusi yang signifikan kepada penguasaan anggota peserta. Dengan memberi tumpuan serius dalam menjalankan penilaian kepada program PMET menerusi kajian-kajian dijalankan akan menjurus kepada penyedian sumber-sumber input dan output 
yang berkemampuan memberikan momentum kepada problem program PMET yang dijalankan. Dengan menjalankan kajian dan pemurnian terhadap kurikulum pelajaran asgar lebih sesuai dan relevan, dengan disusun secara sempurna dan seimbang dalam proses penjadwalan, dibantu oleh kemudahan modern dan canggih yang mampu menarik minat anggota peserta seperti unsur-unsur kreatif multimedia, tempat pelaksanaan yang yang mewujudkan suasana realiti seperti kawasan operasi atau peperangan dan seterusnya dimainkan peranan yang problematis oleh fasilitator semasa proses PdP akan menjadikan kelima-lima elemen utama yang terdapat dalam program PMET memberikan kontribusi yang signifikan kepada penguasaan aspek kognitif dalam kalangan anggota peserta. 


\section{DAFTAR PUSTAKA}

Azizi dan Roslan (2000). Penilaian Terhadap Keberkasusanan Perlaksanaan Program.

Azizi Yahya (2001b). The Using of Model Context. Input, Process and Products (CIPP) In Learning Programs Assessment. International Conference on Challenges and Prospects in Teacher Education, Concorde Hotel : Shah Alam ( 16 \& 17 July 2001)

Azri (2009). Pelaksanaan Program Pendidikan Moral dan Etika Pemerintahan Medan Tentara Darat. Tesis Sarjana. Fakulti Pendidikan, Universiti Malaya.

Bebeau, M. (2002). The Defining Issues Test and the four component model: Contributions to professional education. Journal of Moral Education, 31(3), 271-295.

Berkowitz, M., \& Gibbs, J. (1983). Measuring the developmental features of moral discussion. Merrill-Palmer Quarterly, 29(4), 399-410. Retrieved October 13, 2008, from PsycINFO database.

Cage, N. (1975) The evaluation of teaching effectiveness and teacher education. Proceedings International for Education Seminar. 30 September-4 Oktober 1974, UNESCO.

Frechtling, J.A ( 2007). Logic Modeling Methods in Program Evaluation. San Francisco, CA: Jossey-Bass.

Hammond, R. L. (1973). Evaluation at the local level. Dlm. B. R. Worthen \& J. R. Sanders (pnyt), Educational evaluation: theory and practice, hlmn. 157-169. Belmont, California: Wadsworth.

Jabatan Arah Pendidikan (2008). Arahan Pentadbiran Pendidikan. Kuala Lumpur : ATM.

Arahan Pentadbiran Pendidikan ATM, 2008.

King, P. \& Mayhew, M. (2002). Moral judgment in higher education: insights from the Defining Issues Test [Electronic version]. Journal of Moral Education, 31(3), 247-270. 
Lim, C.H. (2007). Penelitian pendidikan : Pendekatan kuantitatif dan kualitatif. Shah

Alam : McGraw-Hill (Malayasia) Sdn. Bhd.

Markas Medan Tentara Darat (2012). Statistik Kasus Kejahatan dan Narkoba Pemerintahan

Medan Tentara Darat, Sel Provos.

Martinelli-Fernandez, S. (2006). Educating honorable warriors. Journal of Military Ethics, 5(1), 55-66. Retrieved Thursday, February 22, 2007 from the Academic Search Premier database.

Mattox, J. (2005). The moral foundations of Army officership. 387-408. In Snider, D. \& Matthews, L. (2005). The future of the Army profession, $2^{\text {nd }}$ Ed., New York: McGraw-Hill.

Moha Asri (1997). Pembangunan perindustrian di Malaysia : perkembangan dan permasalahan. Shah Alam : Fajar Bakti, Edisi 3.

Snider, D. (2008). Ethics and the human development of the soldier spirit.

The Army Chaplaincy, 23-

33.

Stufflebeam, D. L. \& Shinkfield, A. J. (1990). Systematic evaluation - a self instructional guide to theory and practice. Boston: Kluwer Nijhoff Publishing.

Trochim, W. K. (1999). Intoduction to evaluation. Error! Hyperlink reference not valid. [13 April 2007].

Williams (2010). The Effect of Initial Entry Training on The Moral and Character

Development of Military Police Soldiers. Ph.D Thesis, Walden University. 